\title{
RISING HAPPINESS IN NATIONS 1946-2004 A reply to Easterlin
}

\author{
Ruut Veenhoven and Michael Hagerty
}

Social Indicators Research, 2006, Vol. 79, pp 421-436

http://dx.doi.org/10.1007/S11205-005-5074-X

\begin{abstract}
The 'Easterlin paradox' holds that economic growth does not add to the quality-of-life and that this appears in the fact that average happiness in nations has not risen in the last few decades. The latest trend data show otherwise. Average happiness has increased slightly in rich nations and considerably in the few poor nations for which data are available. Since longevity has also increased, the average number of happy life years has increased at an unprecedented rate since the 1950s.
\end{abstract}

\section{$1 \quad$ INTRODUCTION}

Income per head increased in most nations during the last half of the $20^{\text {th }}$ century, but was this growth in wealth accompanied by rising happiness?

Richard Easterlin claims it has not. In a seminal paper entitled 'Does economic growth improve the human lot?' he argues that happiness remained at the same level in the US between 1946 and 1974, in spite of a doubling in income per head over that period (Easterlin 1974). In later papers Easterlin showed that this pattern persisted in the US and that it also appears in other countries (Easterlin 1995, 2004). This position has come to be known as the 'Easterlin paradox' and is generally taken as a fact.

We challenged this view in a recent article in this journal, entitled Wealth and Happiness Revisited: Growing National Income Does Go with Greater Happiness (Hagerty \& Veenhoven 2003). In the paper we presented the trend data on average happiness in 21 nations for the years 1972-1994 and showed that happiness had increased in most of these nations, including the USA. Consequently we found a positive correlation with economic growth.

Richard Easterlin elegantly disputed these findings in a paper: Feeding the Illusion of Growth and Happiness: A Reply to Hagerty and Veenhoven, published in this journal (Easterlin 2005).

\subsection{Easterlin's objections}

Richard Easterlin starts with our conclusion that happiness had risen in most countries. He argues that we observed an upward trend in the USA because we did not limit ourselves to the time-series of the General Social Survey, but that we also included responses to similar items drawn from other surveys, which has distorted the picture. With respect to Western Europe he points out that happiness has not risen in all countries and that the overall pattern shows little or no trend. Easterlin deems our data on trends of 
happiness in developing nations to be 'fragmentary' and is therefore skeptical of our claim that happiness has also risen in these countries. He states that we should focus on the case of Japan, where wealth has increased considerably, yet happiness levels have stagnated.

Next Easterlin criticizes our conclusion that happiness goes with economic growth in most cases. He argues that we should have counted the cases of significant correlation only, which would leave us with 7 out of 21 cases instead of 14 . In his view, the cases of correlation are exceptions rather than the rule. He further notes that the correlation is smaller among poor countries, while our theory would predict otherwise.

\subsection{Background to the disagreement}

The difference arises from the fact that the available data are not always too clear and therefore allow different interpretations. Easterlin reads the data as showing that the glass is half empty, while we see the glass to be half full. There are several reasons for this ambiguity:

One reason is that changes in happiness are typically small. Unlike wealth, happiness ratings are bound to an upper limit and nations that score high are unlikely to increase much over short periods of time. So we need long time series to see whether happiness has risen or not, and most of the available time series cover no more than a few decades.

Another reason is that the trend is probably not smooth. Average happiness in nations tends to fluctuate slightly, among other things as the result of ups and down in the economy (Chin Hon Foei 1989). Ruling out such fluctuations also requires sizable time series to estimate the long-term trends and preferably with a lot of data points in these series.

Our view on these small and variable changes is further limited by inevitable imperfections to be found in the ways we measure happiness. The survey questions used for assessing happiness are not identical, where questions are placed during interviews is not always the same, some survey programs have changed from face-to-face to telephone interviewing, and so on. This problem is illustrated by the fact that assessments made in the same year using identical questions differ on average by 0,2 points on the $0-10$ scale $^{1}$.

This problem of inaccuracy can be handled in two ways, one way is to limit oneself to using data for which the assumption can be made that all the data are collected using the same method. The other way is to make the assumption that including all the available data will cause the variety to be neutralized by the law of large numbers. In the case of the USA Easterlin opted for the former solution and focused on the General Social Survey. We opted for the latter and included all the available data. Our approach makes more sense in the long term, as more data becomes available so the law of large numbers will become more valid.

\subsection{Approach of this reply}

Of late, the amount of data on happiness in nations has increased considerably. New data been added, and earlier findings, not previously available in the database, have also been added. We now have longer time series on more nations and the information about happiness in the USA has been enriched with additional time series from the Gallup archive (Gallup Brain), recently published by Jones (2004), Saad (2004) and Carroll 
(2005). All these new data have been entered in the World Database of Happiness, section 'Distributional Findings in Nations' (Veenhoven 2005a).

We will now consider what this data tells us about the trends in people's happiness in different nations for the last decades. In our view, this is more productive than quarreling over yesterday's evidence, and, we frankly admit, this allows us to bypass much of Easterlin's well-taken criticism.

We will begin with the case of the USA, which stands out in this discussion. Next we will consider the trend in happiness in other rich nations and lastly we will take stock of the few available data on happiness in poor nations

\section{HAS HAPPINESS RISEN IN THE USA?}

Public happiness is assessed using different questions on subjective appreciation of lifeas-whole. These questions can differ in wording of the lead item and in rating of the responses. These differences are too large to allow comparison over time. Hence we will consider time series for specific questions separately and we will limit ourselves to items that have been used in at least 10 different years ${ }^{2}$ over a 25 -year period.

For reasons of comparability we will use the transformed means provided in the World Database of Happiness. The transformed means are expressed on a common numerical scale ranging from 0 (low) to 10 (high). Scores on numerical response scales, shorter than this, are linearly stretched to give a range of $0-10$. Scores on scales with verbal response options are transformed using a procedure first described by Thurstone, in which experts rate the numerical value of response options. This procedure has the additional advantage that slight differences in the wording of response options can be taken into account, for instance the response 'not happy' is rated higher than the response 'not at all happy'. This procedure is described in Veenhoven (1993: 108-118). A largescale replication of this scale homogenization study is currently being carried out (Veenhoven \& Kalmijn 2006).

\section{$2.1 \quad$ 4-step happiness}

The first American survey that involved a question about happiness was Gallup's 'Public Opinion Survey' number 417, which was held in February 1946. The question read:

In general, how happy would you say that you are?

- very happy

- fairly happy

- $\quad$ not very happy

- not at all happy

Later AIPO polls around 1950 used similar questions with slight variations in wording, the last responses option being variably worded as 'not at all happy' or 'not happy'. The same item has been used in several Gallup surveys since 1980.

The average scores on this item over the years are depicted in figure 1 . As one can see the average scores have remained at the same level, the regression line shows no visible slope. 


\section{$2.2 \quad 3$-step happiness}

In June 1947 AIPO poll 399 introduced a 3-step question on happiness that read:

In general, how happy would you say you are?

- very happy

- fairly happy

- not at all happy

In later variations the last option was worded as 'not very happy', 'not happy' and 'not too happy'. In May 1963 NORC fielded the following variation:

Taking all together, how would you say things are these days? Would you say that you are...?

- very happy

- pretty happy

- not too happy

This question became standard in the periodical General Social Surveys (GSS) that started in the USA in 1971 and continues to the present day, the latest survey was held in 2004.

The average scores on this item are plotted in figure 2. Again the regression line looks flat. The idea that average happiness has not changed in the USA is based on the responses to this question.

\section{$2.3 \quad$ 11-step worst-best possible life}

In 1959 Hedly Cantril introduced a different question and asked Americans to rate their present life on a ladder scale ranging from what they imagined to be the worst possible life (0) to their notions of the best possible life (10). The advantages of this way of questioning are that it allows for more differentiation in response and the question is more clearly focused on a respondent's present life. To date, this question has been used in 19 surveys in the USA. The average scores are presented in figure 3 , in which a rising trend is revealed.

\section{$2.4 \quad$ 2-step life-satisfaction}

Since 1979 Gallup polls have contained a question regarding satisfaction with personal life following a question regarding satisfaction with life in the US. This item allows only two response-options, that is: 'satisfied' or 'dissatisfied'. The responses to this question are plotted in figure 4 and also show an upward trend.

\subsection{Why not equally positive?}

The trends in responses to the four items are summarized in table 1. All four regression coefficients are small but positive. Two are so small that they do not reach the 5\% significance level. Why are not all the trends equally strong?

One explanation could be that the items tap slightly different phenomena, and that Americans have become more satisfied, but not happier. If so, measures of mood should also show stability or possibly a slight decline. Yet scores on the Affect Balance Scale 
have gone up in the USA: 6,7 in the 1970s, 7,0 in 1981 and 7,2 in $1990^{3}$ (WDH table 222).

Another explanation could be that the questions on happiness are more prone to random error, possibly because the term happiness is difficult to specify. If so, this random variation may have overshadowed the small trend. There are indeed indications that the explained variance in responses to questions using 'happiness' as a keyword is lower than for questions using the term 'satisfaction' (e.g. Lynn \& McGrahanan 1980). It is also possible that the term happiness is more often associated with a stable characteristic than with variable states of satisfaction and that these items are therefore less sensitive to change.

Still another possibility is that the stray data points found before 1970 distort the picture. Indeed all trends after this time are significantly positive, even the trend on 3-step happiness, $\mathrm{B}=+0,011$ [CI95: $+0,003$ to $+0,019$ ]. Yet this still leaves us with the question of why Americans would have rated their happiness relatively high in the post-war decades and whether such a difference is to be seen as true happiness or distorted assessment.

Lastly, the differences could be due to things we cannot determine, such as differential interviewer bias or the questions being asked in a different order in the questionnaire.

\subsection{Overall trend}

Given these ambiguities, what is the best characterization for the trend in happiness in the USA over these years? If we refrain from valuing one kind of findings above others, our best resort is to take an average. This is what we did. We computed the average regression coefficient, weighting for the number of time points. This produced an average yearly increase of $+0,006$. At this rate it will take 167 years to gain one full point on the 0 to 10 scale of happiness. A modest change indeed, but such a small change is not uncommon in long-term development. For instance: Maddison (1995) estimates that the world economy grew at a rate of only $+0,0004$ per year between 1500 and 1820 .

\section{TREND IN HAPPINESS IN THE EU-8}

It is easier to assess the trend in happiness in the European Union, at least in the eight member states that have participated in the Euro-barometer survey from the beginning. This survey has been held twice a year since 1973and the same question on lifesatisfaction was used consistently throughout this time. It reads as follows:

On the whole, how satisfied are you with the life you lead?

- very satisfied

- fairly satisfied

- not very satisfied

- not at all satisfied

The consistency of the question and the massive number of data-points allows us to make a better estimation of the trend in happiness in the EU than in the USA. To get a better view on the general trend we aggregated the data and computed yearly averages for all 
the EU-8 nations, which we then weighted according to population size. The trend-plot of these data is presented in figure 5. A small but positive trend emerges, the regression coefficient is $+0,008$ and the $95 \%$ confidence interval ranges from $+0,004$ to $+0,012$. Note that the variation around the regression line is quite small in this case, which indicates that we successfully weeded out random variation. Not surprisingly, the pattern is less pronounced when we consider each of the nations separately. The trend is significantly positive in only four of these nations (Denmark, France, Italy and Luxembourg) and significantly negative in the case of Belgium (Veenhoven 2005c). The negative trend in Belgium is due to a profound decline in happiness in the early 1980s that ran parallel with a slow down in Belgium's economy (Hagerty and Veenhoven 2003: 15).

\section{TREND OF HAPPINESS IN DEVELOPING NATIONS}

Estimation of the trend in happiness in developing nations is less easy. One problem is that happiness has been assessed in only a few of these nations and another is that the number of time points is often no more that two or three, with the additional complication that different questions have been used.

Thus we limit to ourselves to the few countries where similar items have been used over a period of at least 20 years. Given the small number of observations, there is little sense in computing regression coefficients and assessing the statistical significance of these. We therefore limit ourselves to noting the difference between the first and the latest scores on the 0 to 10 scale of happiness for a developing nation.

\subsection{1-step best-worst possible life}

The most commonly used question is a rating on the ladder of life as mentioned above. This question was used for several developing nations that participated in Cantril's study on the Patterns of Human Concerns in the early 1960s. Variants of this question have also been used in later surveys in developing nations, in particular in the Gallup-Kettering World survey in the mid 1970's and in the recent international Penn-survey. Data were taken from the World Database of Happiness. Following Easterlin, we also included Japan and Korea, countries that were still developing in the early 1960s. The results are presented in table 2. As can be seen from the figure, the trend is positive for all of these few cases.

\subsection{Questions on 'happiness'}

There are a few cases that allow a comparison of responses to identical questions on happiness over time. The results are presented in table 3, and again we see a gain in most cases. Only in South Korea has happiness stagnated.

These gains in average happiness are all statistically significant, given that we have sample sizes of more than 1000 a difference of 0,3 is significant at the $5 \%$ level, and the differences in table 2 and 3 are much larger than this.

This increase in happiness in developing nations is much larger than the gains observed in the US and the EU-8. In the US the score on the Cantril ladder increased by 
0,36 points between 1959 and 2004, while the gain in happiness between 1980 and 2000 was about 0,04. The average gain in life-satisfaction in the EU-8 between 1973 and 2004 was 0,17 . This pattern fits the theory that increasing wealth is subject to the law of diminishing returns.

\section{$5 \quad$ DISCUSSION}

All in all, it seems that people have become happier in the second half of the $20^{\text {th }}$ century and that the gains in happiness have been greater in poor nations than in rich nations. Yet the data are not unequivocal and there are still many blank spots. Moreover, the overview of the general pattern is still limited by imperfections in measurement and incidental variation. Obtaining certainty must wait until longer and better time series become available.

This inquiry into trends in happiness is part of a wider discussion on the merits of economic growth. In this discussion, average happiness is used as an indicator of qualityof-life, and in this context it is worth noting that the quality-of-life in nations is better measured when longevity is also taken into account, a long and happy life being more valuable than a short but happy life. Data on average happiness and longevity in nations can be combined in a measure of Happy Life Years (Veenhoven 1996, 2005g). Since life expectancy has increased considerably in the $20^{\text {th }}$ century, this combined measure shows much greater gains over time than happiness alone. In the period 1973-2004 Americans gained 5,2 happy life years and Western Europeans 6,3 years (Veenhoven 2005d). In the light of this unprecedented improvement one cannot maintain that we do not live better than we did in the past.

Another issue in the discussion on the merits of economic growth is its effect on social inequality, critics claiming that increasing wealth is bought at the cost of a deepening split in society between the haves and the have-nots. In this context it is worth noting that there is no evidence of a growing disparity between happy and unhappy citizens in rich nations. The reverse has happened, inequality of happiness in nations has diminished and this trend is more pronounced that the modest rise in average happiness (Veenhoven 2005e, 2005h). This is still another indication that our lives are better today.

Incomes per head have grown in all the countries considered here and, since happiness has also increased in most cases, there is a correlation between growth of wealth and happiness. Easterlin rightly notes that correlation does not necessarily mark causation, and we acknowledged this in our 2003 paper, on page 23. Things that go with economic growth, such as the emancipation of women or better self-understanding can cause the gains in happiness, rather than just a growth in the available wealth. In a wider perspective, our reclaiming of freedom following the industrial revolution seems to be one of the crucial reasons for the observed gain in happy life years (Veenhoven 2005f).

It is still possible that increasing wealth has caused the rise in happiness and there is evidence that things have worked out in this way in the cases of Russia and East Germany. In Russia average happiness decreased by two points following the Rubelcrisis in the mid 1990s, which severely disorganized the economy. As the Russian 
economy begun to pick up, so happiness also began to rise (Veenhoven 2005c). This effect has also been demonstrated in a follow-up at the individual level. Russians who have done well economically became happier, while Russians who have lost out economically have become less happy (Graham, 2004). Likewise, Frijters et. al. (2004) have shown that money did matter in East Germany in the decade after re-unification, higher real household incomes leading to a significant gain in life-satisfaction.

We acknowledge that a growth in wealth does not always work out this way. There are positive and negative effects of economic growth and the balance of effects will vary with circumstances. One of the conditions in which negative effects may cancel the positive is when economic development induces profound cultural change. This may be the case in Japan and South Korea, which have gained less in happiness than might be expected given the startling growth in material wealth in these countries. Possibly this is a temporary lag. One of the challenges for future research will be to chart these contingencies and to distinguish short-term variations from long-term trends.

\section{CONCLUSION}

Life became better in most countries in the last half of the $20^{\text {th }}$ century. Life is not only more satisfying for the average citizen, but the citizen's average lifetime has also been extended. Taken together this results in considerable gains in happy life years. This improvement in the quality of life has come about hand-in-hand with growing wealth, and in some cases at least, there is evidence for causal effects. 


\section{NOTES}

${ }^{1}$ This estimate is based on average scores reported in the World Database of Happiness, section 'Distributional Findings in Nations (Veenhoven 2005)

${ }^{2}$ When happiness has been assessed in more than one survey in the same year, we take the average.

3 These findings were not reported above, because this series does not meet the requirement of at least 10 year points and more than two decades. 
Table 1

Observed trends in responses to five self-report measures of happiness in the USA

\begin{tabular}{|l|c|c|c|c|}
\hline Item & Era & N & B & CI 95 \\
\hline 2-step life satisfaction & $1979-2004$ & 22 & $+\mathbf{0 , 0 1 6}$ & $+0,008$ to $+0,024$ \\
\hline 3-step happiness & $1947-2004$ & 40 & $+0,002$ & $-0,003$ to $+0,007$ \\
\hline 4-step happiness & $1946-2002$ & 12 & $+0,002$ & $-0,006$ to $+0,010$ \\
\hline $\begin{array}{l}\text { 11-step best worst } \\
\text { B average } \\
\text { weighted for N data points }\end{array}$ & $1959-2005$ & 19 & $+\mathbf{0 , 0 0 8}$ & $+0,000$ to $+0,017$ \\
\hline
\end{tabular}


Table 2

Trend in average response to question on 'best-worst possible life' in 8 developing nations

\begin{tabular}{|l|c|c|}
\hline Nation & Period & $\begin{array}{c}\text { Difference in mean score on 0-10 scale } \\
\text { between first and latest observation }\end{array}$ \\
\hline Brazil & $1960-2002$ & $+\mathbf{1 , 4 6}$ \\
\hline Egypt & $1960-2003$ & $+\mathbf{0 , 8 8}$ \\
\hline India & $1962-2002$ & $+\mathbf{1 , 1 0}$ \\
\hline Japan & $1962-2002$ & $+\mathbf{0 , 6 8}$ \\
\hline Korea & $1981-2002$ & $+\mathbf{2 , 1 8}$ \\
\hline Mexico & $1959-2002$ & $+\mathbf{0 , 6 0}$ \\
\hline Nigeria & $1962-2002$ & $+\mathbf{1 , 0 5}$ \\
\hline Philippines & & $+\mathbf{0 , 5 7}$ \\
\hline
\end{tabular}

Source: World Database of Happiness, Distributional Findings in Nations, Table 131B 
Table 3

Trend in average response to the same question about 'personal happiness' in 4 developing nations

\begin{tabular}{|l|c|c|}
\hline Nation & Period & $\begin{array}{c}\text { Difference in mean score on 0-10 scale } \\
\text { between first and latest observation }\end{array}$ \\
\hline Japan & $1981-2000$ & $+\mathbf{0 , 5 3}$ \\
\hline Mexico & $1981-2000$ & $+\mathbf{0 , 9 6}$ \\
\hline South Africa & $1981-2001$ & $+\mathbf{0 , 7 0}$ \\
\hline South Korea & $1981-2001$ & $\mathbf{- 0 , 0 6}$ \\
\hline
\end{tabular}

Data: World Database of Happiness, Distributional Findings in Nations, Table 111B 
Figure 1

Trend 4-step happiness in the USA 1946-2004

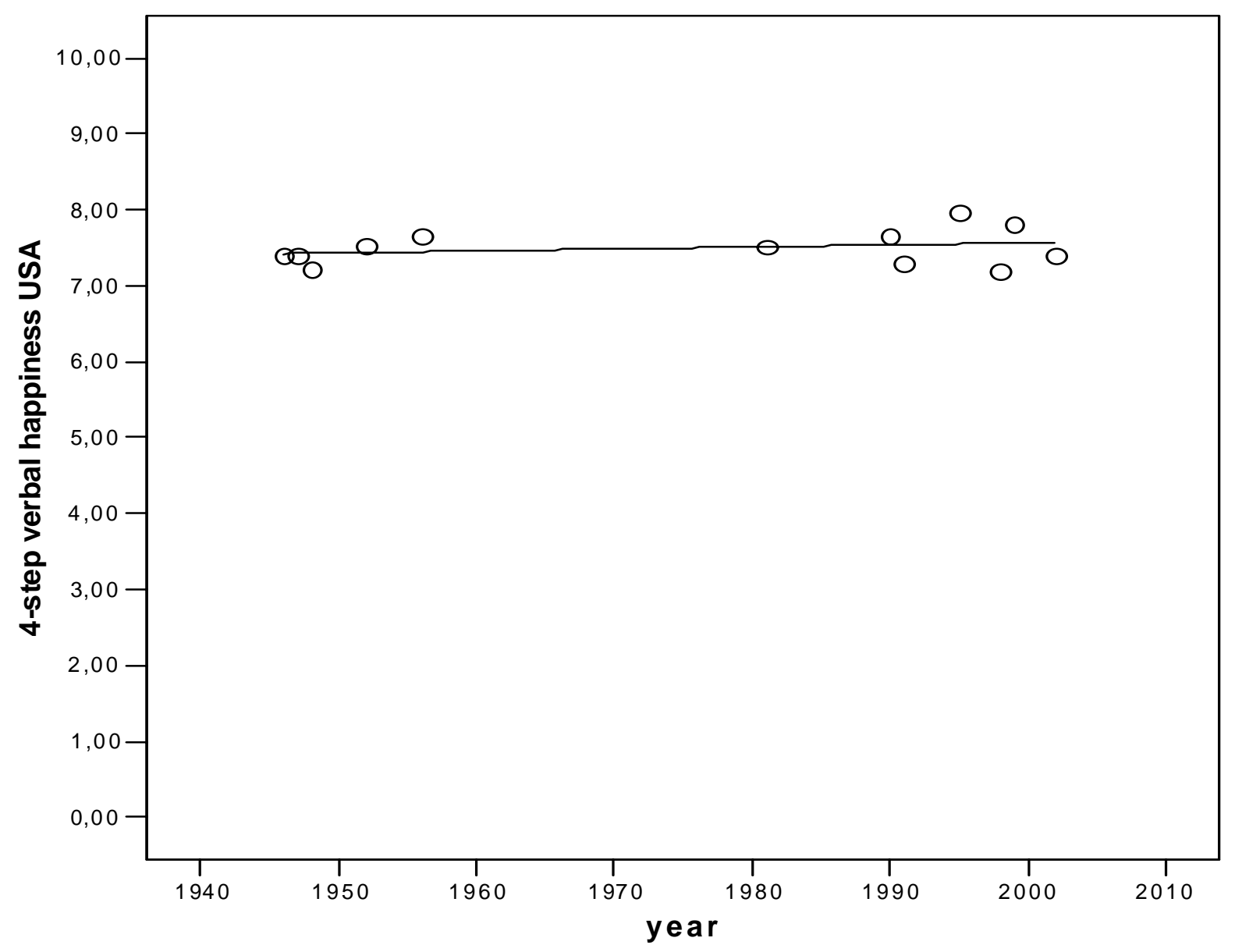


Figure 2

Trend 3-step happiness in the USA 1947-2004

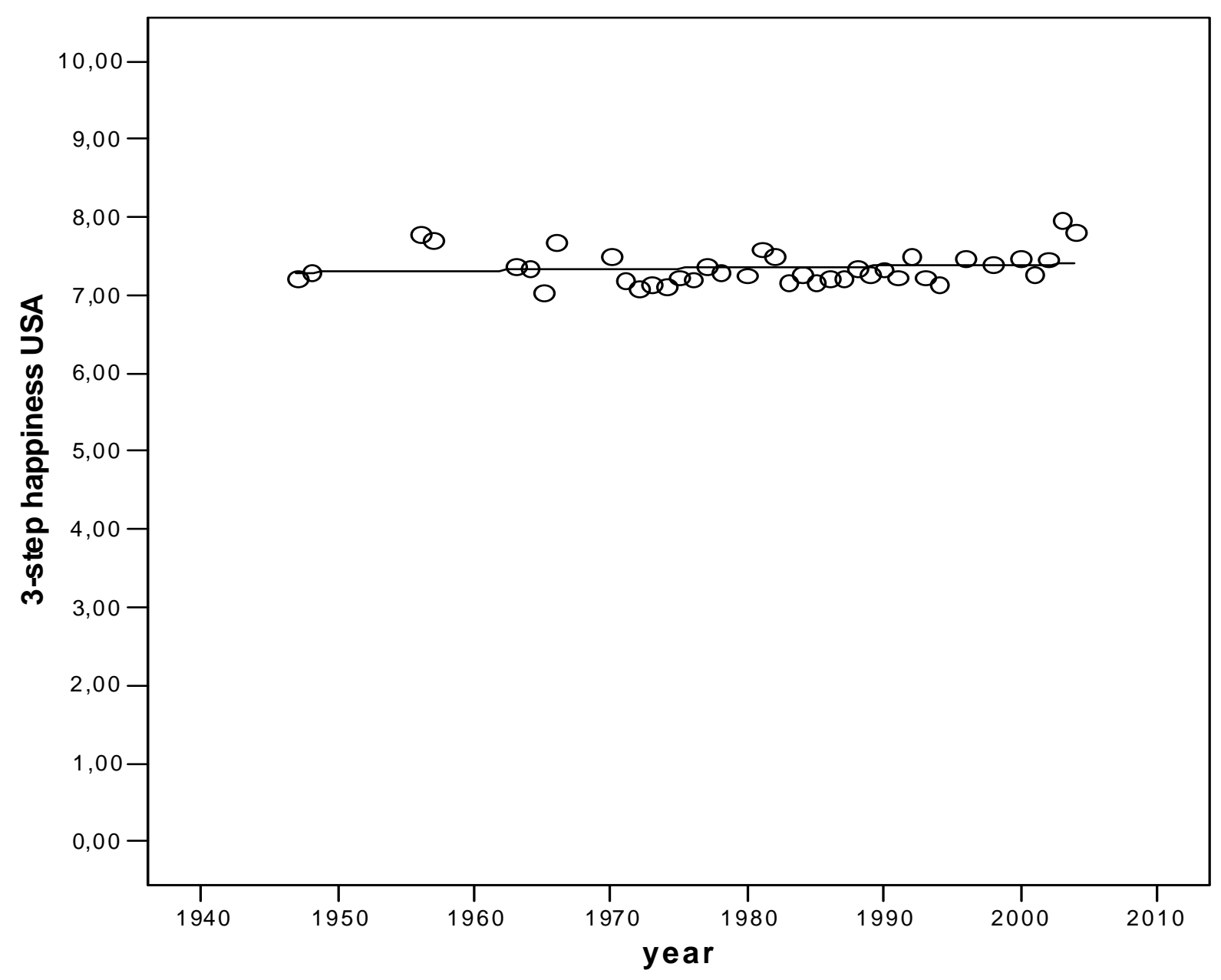


Figure 3

Trend 11-step Best-Worst ladder rating in the USA 1959-2004

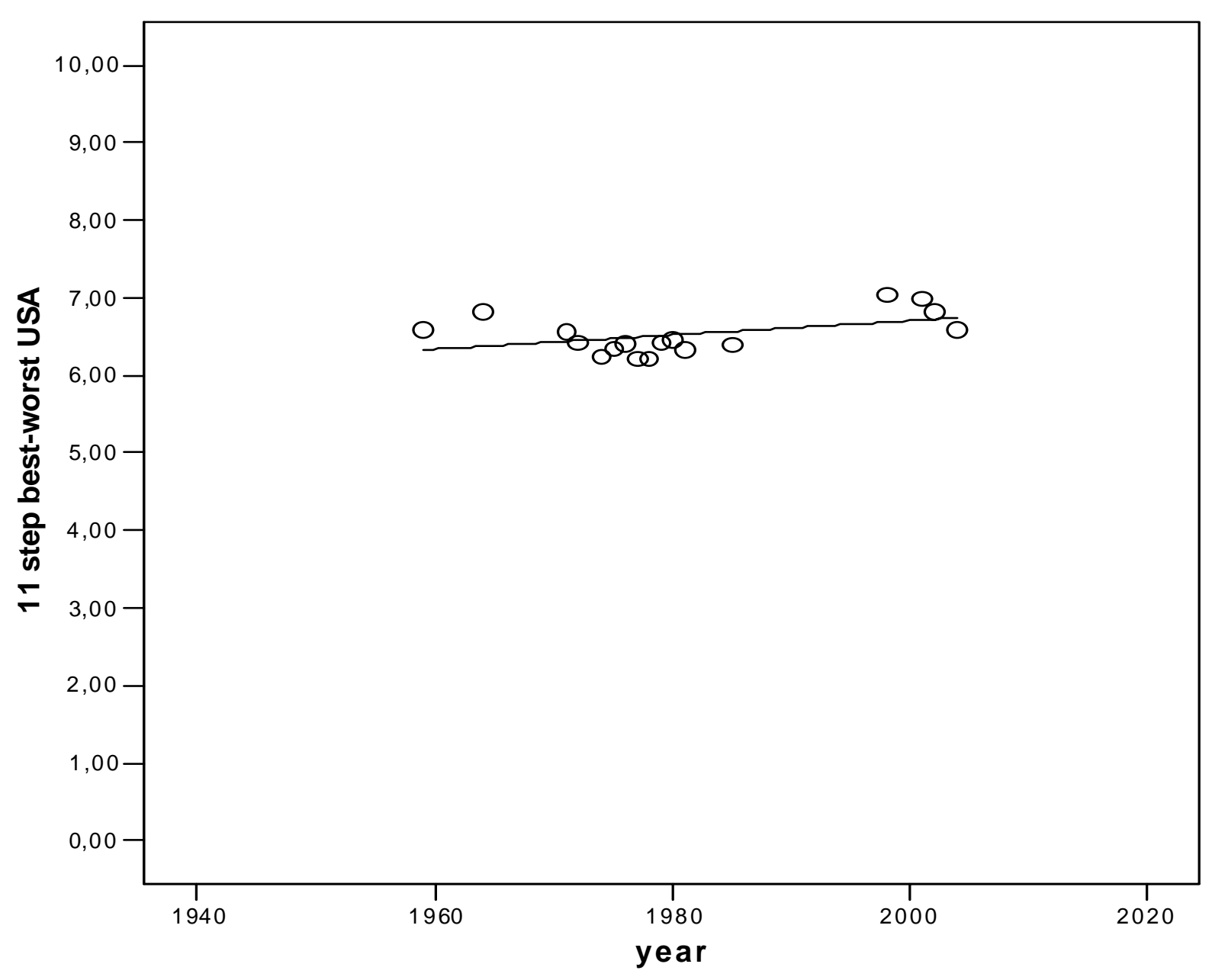


Figure 4

Trend 2-step life-satisfaction in the USA 1978-2004

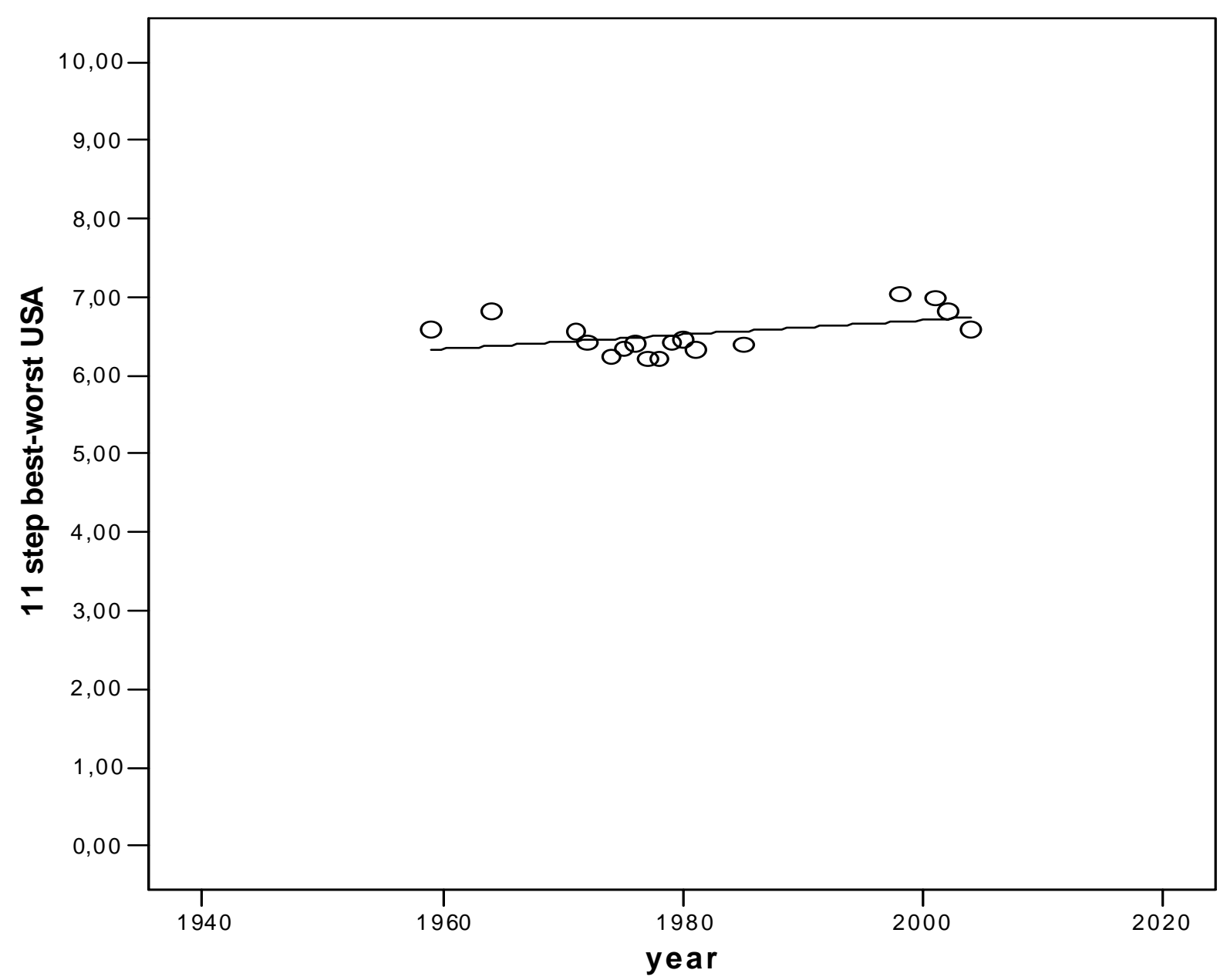


Figure 5

Average happiness in Western Europe 1973-2004

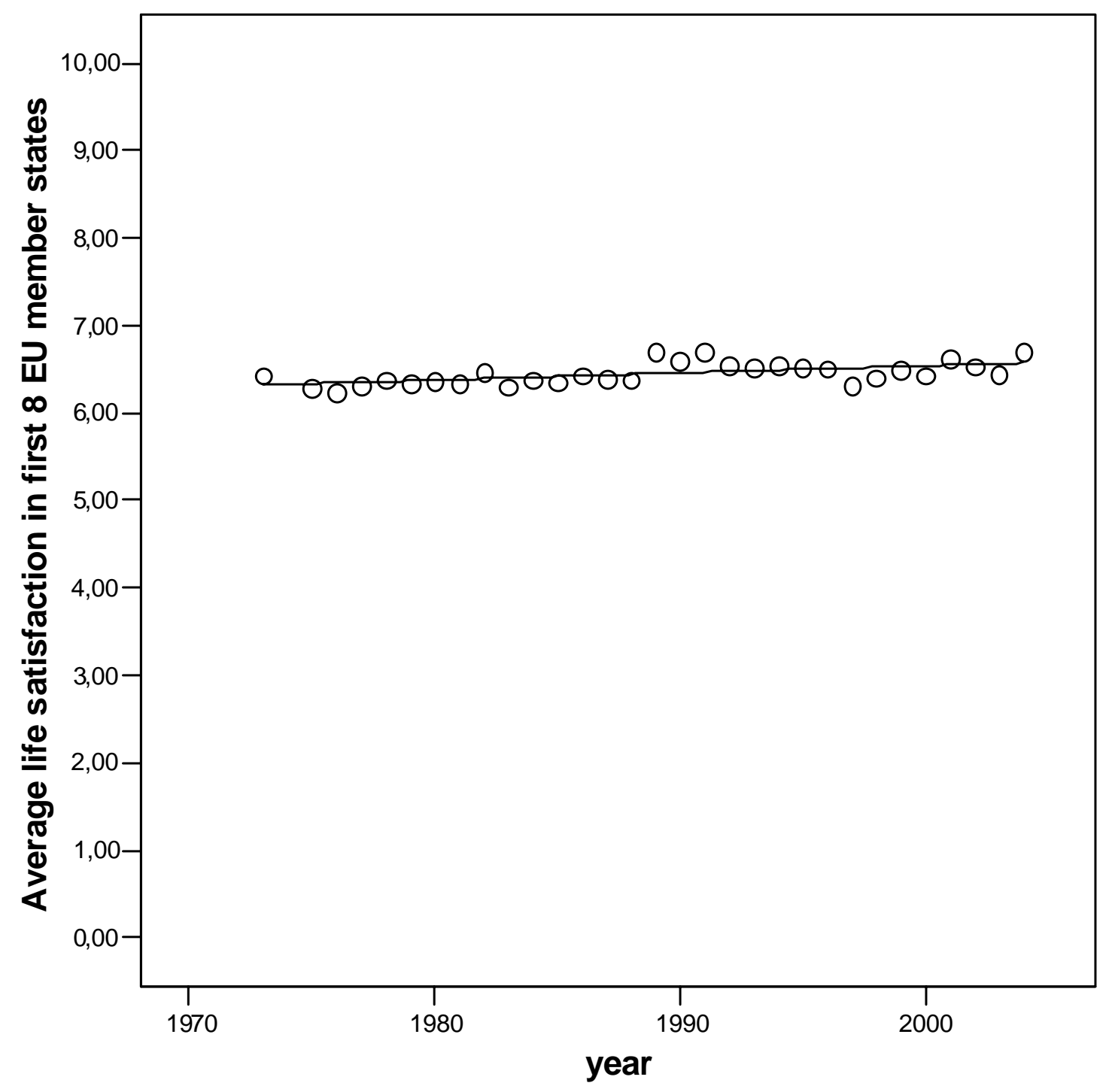




\section{REFERENCES}

Carroll, J. (2004)

Americans personal satisfaction

Gallup Polls News Service, 4 January 2005, Gallup Organization, Washington DC, USA-

Chin-Hon-Foei, S (1989)

Life-satisfaction in the EC-countries 1975-1984

In: Veenhoven, R. \& Hagenaars, A. (eds): Did the crisis really hurt? Effects of the 1980-

82 economic recession on satisfaction, mental health and mortality

Universitaire Pers Rotterdam, The Netherlands

Easterlin, R.A. (1974)

Does economic growth improve the human lot?

In: Paul A David and Melvin W. Reder (Eds) 'nations households and economic growth: essays in honor of Mozes Abramowitz, New York, Academic press

Easterlin, R.A. (1995)

Will raising the income of all increase the happiness of all?

Journal of Economic Behavior and Organization, vol. 27, pp. 35-48

Easterlin, R.A. (2003)

Explaining happiness

Proceeding of the National Academy of Sciences, vol. 100, pp. 11176-11183

Easterlin, R.A (2005)

Feeding the illusion of growth and happiness: A reply to Hagerty and Veenhoven

Social Indicators Research, vol. 74, pp.429-443

Frijters, P., Haisken-DeNew, J/P. \& Shields, M.A. (2004)

Money does matter! Evidence from increasing real income and life-satisfaction in East

Germany following Reunification

The American economic review, vol. 94, pp. 730-740

Gallup Brain

Web archive of public opinion polls since the 1930s

http://www.brain.gallup.com

Graham, C. (2004)

Does Happiness Pay? An Exploration Based on Panel Data from Russia

Journal of Economic Behavior, Vol. 55, 319 - 342

Hagerty, M R. \& Veenhoven, R. (2003)

Wealth and happiness revisited: Growing national income does go with greater

happiness

Social Indicators Research, vol. 64, pp. 1-27 
Jones, J.M. (2004)

Americans: Life is good and will only improve

Gallup Poll News Services, 17 February 2004, The Gallup Organization, Washington

DC, USA

Linn, G.J. \& McGranahan, D.A. (1980)

Personal disruption, social integration, subjective well- being and predisposition toward the use of counseling services

American Journal of Community Psychology, vol. 8, 87-100

Maddison, A. (1995)

Monitoring the world economy, 1820-1992

OECD, Paris

Saad, L. (2004)

A nation of happy people: Most Americans are happy and satisfied with their life

Gallup Poll News Services, 5 January 2004, Gallup Organization, Washington DC, USA

Veenhoven, R. (1993)

Happiness in nations

RISBO, Rotterdam, The Netherlands

Veenhoven, R. (1996)

Happy Life expectancy: A comprehensive measure of quality-of-life in nations

Social Indicators research, vol. 39, pp 1-58

Veenhoven, R. 2005a

World Database of Happiness: Continuous register of research on subjective appreciation of life

Erasmus University Rotterdam, The Netherlands: http://worlddatabaseofhappiness.eur.nl

Veenhoven, R. (2005b)

Average happiness in 90 nations 1990-2000

RankReport 2005/1, World Database of Happiness, http://worlddatabaseofhappiness.eur.nl

Veenhoven, R. (2005c)

Trend average happiness in nations: 1946-2004

Trendreport 2005-1d, World Database of Happiness; http://worlddatabaseofhappiness.eur.nl

Veenhoven, R. (2005d)

Trend Happy Life Years in nations: 1946-2002

Trendreport 2005-2a, World Database of Happiness;http://worlddatabaseofhappiness.eur.nl

Veenhoven, R. (2005e)

Trend inequality of happiness in nations: 1946-2004

Trendreport 2005-1d, World Database of Happiness; http://worlddatabaseofhappiness.eur.nl 
Veenhoven, R. (2005f)

Is life getting better?

European Journal of Psychology, vol. 10, pp. 330-341

Veenhoven, R. (2005g)

Apparent quality-of-life in nations: how long and happy people live

Social Indicators research, vol. 71, pp. 61-86

Veenhoven, R (2005h)

Return of inequality in modern society? Test by trend in dispersion of life-satisfaction across time and nations

Journal of Happiness Studies, vol. 6, in press

Veenhoven, R. \& Kalmijn, W.M. (2006)

How happy is 'very' happy? International scaling study

Research report in preparation 